Program Accomplishment Under USDOE Grant DE-FGO2-84ER.45095

Two areas have been focused on in the current period: ciusters of $B i$ grown on surtiaces and materials formed from buckyball (c60) clusters.

\title{
Bismutin Researeh
}

of iilajor importance in the area of clusters and nanoscale materials is the size for which the system transforms to a different structure than its bulk form. Our Raman scattering and TEM studies of $B i$ have provided a means of studying the transition from the equilibrium rhombohedral phase present in larger nanocrystalline clusters to a noncrystalline, amorphous phase. Modeling of the Raman and TEM measurements have shown that this transition is enhanced by the coalescence of amorphous Bi particles. The transition is found to occur at $\sim 1300$ atoms/cluster. this is the first work that establishes a tramsiticn size for any class of cluster materials.

A conparison of the amorphous Bi cluster spectra with inelastic tunneling phonon studies of metallic amorphous Bi thin films have demonstrated that the present elusters have a different local structure and bonding. This is indicated by changes in the Raman spectra which point to the Bi clusters being amorphous semiconducting in character.

The effect of $H$ on the coalescence of amorplous $B i$ clusters has also been studied by Raman and TEM. Recent results have demonstrated that atomic $H$ surprisingly induces cluster motion Even at low temperatures of 21 lok: This mability induced coalescence differs from growth induced coalescence noted above 
in its more dramatic influence on the transformation from amorphous to nanocrystalline cluster struetures. TEM and Raman studies show that motion of larger clusters in the size distribution that are amorphous are induced to move short distances. Subsequent coalescence with adjacent particles then results in a sufficient number of atoms for an amorphous to nanocrystalline transformation to occur. Student participation: Michael Miteh

\section{Buckyball Research}

The structure and dynamics of C60 has been performed on material separated from $\mathrm{C} 60$ and $C 70 \mathrm{mixtures}$ obtained from Smalley's Rice group. Separation, performed by Fang Li, who has graduated, and David Ramage of Chemistry resulting in the preparation of a very large sample for neutron scattering studies of the dynamics and structure of pure c60. The dynamics study, in collaboration with a group at NIST, yielded the first detailed measurement of all the intramolecular vibrations of cbo.

Structural studies of C60 were performed at Argonne IPNS where radial distribution functions were obtained. Very high $Q$ measurements provided a means of obtaining an accurate radial distribution function. The major results provided direct confirmation of the truncated icosohedral structure by exhibiting 13 distinct features at the correct position ratios for the proposed fullerene structure. In addition, the data have provided a more accurate estimates of the basic single and double bond distances of C60 of $1.39 \mathrm{~A}$ and $1.46 \mathrm{~A}$. This is of basic importance to modeling of thine fundamentai properties of cbo and improves on values obtained by other methods. 
A program of Raman scattering of ultrathin $A \times C b O(A=R b, K$, Na) buekyball films was initiated to obtain information on interactions with surfaces as well as address the effects of alkali dopant relevant to superconducting materials. These studies, performed in our special UHV system, have provided very important information on the mechanism for superconductivity in these materials. Specifically, using ultrathin films made in UHV we have been able to form a continuous range of solid solutions of variable metallic character and follow the metallic behavior with Raman scattering. In contrast, normal thin films allow only compounds of $x=0,3,(4)$ and 6 to form. Our results demonstrate quite clearly that phonon-mediated superconductivity is the likely mechanism in these materials. In addition, changes in the behavior of the different Raman modes of doped c60 indicate which modes influence the electrons. Of special importance is the observation that both lower frequency modes involving radial displacemerits of carbon atoms on the buckyball as well as tangential motions are required. This is significant, since zeveral recent theories have not included the radial motion. To date, only the theory of schluter et al of ATDT have radial and tangential displacements.

\section{Student participation:}

Fang Li - Structure of C60 (Ph. D. Completed in summer 1991) Michael Mitch - Raman scattering (3rd year Ph. D. Student) Sabrina Chase - X-ray Photoemission (3rd year Ph. D. Etudent) 
-Papers published

"Raman Scattering and Photoemission from Bi Clusters", M.G. Mitch, S.G. Chase, R.Q. Yu, J. Fortner and J.S. Lannin, in MRS Proc. 206, Clusters and Cluster Assembled Materials, ed. R>S. Averbach, J. Bernhole and D.L. Nelson (MRS, Pittsburgh, 1991) P. 49 .

"Phase Transition in Ultrathin Bi Films", M.G. Miteh, S.L. Chase, J. Fortner, R.Q. Yu and J.S. Lannin, Phys. Rev. Lett. 67, 875 $(199:)$.

"Phase Transitions and Coalescence Phenomena in Bi Clusters", Proc. Intern. Symp. Physics and Chemistry of Finite Systems: From Clusters to Crystals, NATO Proceedings (in press).

"Neutron Measurements of Intramolecular Vibrational Modes of C60", R.L. Cappelletti, J.R.D. Copley, W.A. Kamitakahara, Fang Li, J.S. Lannin and D. Ramage, Phys. Rev. Lett. 66, 3261 (1991).

"Radial Distribution of C6o - Structure of Fullerene", Fang Li, D. Ramage and J.S. Lannin, Phys. Rev. Rapid Commun, Dec. 15, 1991.

"Structure of Fullerene", Proc. Intern. Symp. Physics and Chemsitry of Finite systems - From Clusters to Crystals, NATO Proceedings (in press).

"Raman Scattering and Electron-Phoron Coupling in RbxC60", M.G. Mitch, J.L. Chase and Z.S. Lennin Isuhmitted to Phys. Rev. Lett.j 


\section{DISCLAIMER}

This report was prepared as an account of work sponsored by an agency of the United States Government. Neither the United States Government nor any agency thereof, nor any of their employees, makes any warranty, express or implied, or assumes any legal liability or responsibility for the accuracy, completeness, or usefulness of any information, apparatus, product, or process disclosed, or represents that its use would not infringe privately owned rights. Reference herein to any specific commercial product, process, or service by trade name, trademark, manufacturer, or otherwise does not necessarily constitute or imply its endorsement, recommendation, or favoring by the United States Government or any agency thereof. The views and opinions of authors expressed herein do not necessarily state or reflect those of the United States Government or any agency thereof. 

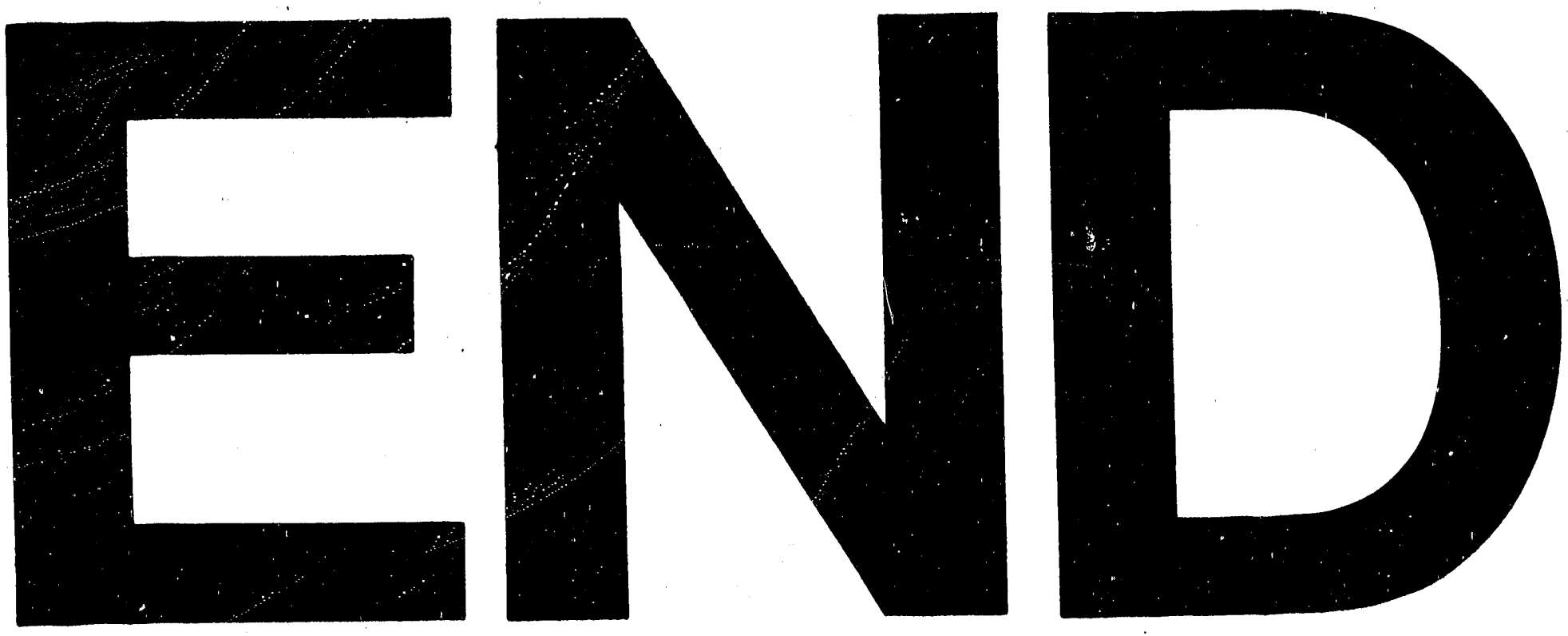

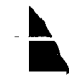
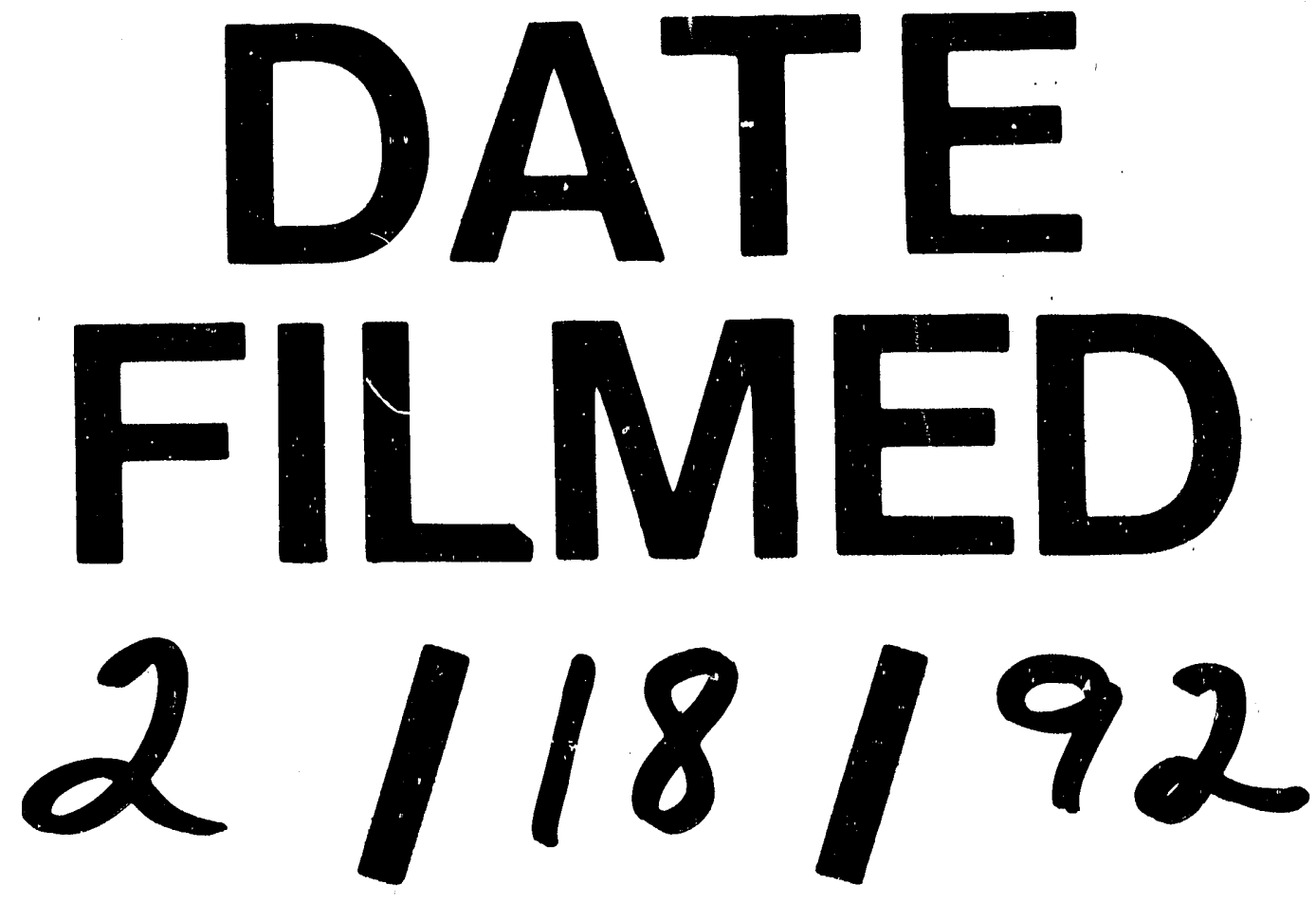
